\title{
La racionalidad delirante: el racismo científico en la segunda mitad del siglo XIX
}

\begin{abstract}
RESUMEN: Una crítica epistemológica a la idea neopositivista de 'racionalidad científica' a partir de un análisis del racismo implícito en los conceptos científicos ortodoxos sobre la diversidad biológica humana durante el periodo de aceptación de las tesis darwinistas sobre el origen evolutivo de nuestra especie.

PALABRAS CLAVE: Racismo científico, racionalidad científica, biología humana, siglo XIX.
\end{abstract}

SUMMARY: An epistemologic critique to the neo-positivist concept of 'scientific rationality'. It is based on an analysis of biological racism, as it permeates orthodox scientific concepts about human diversity during the period in which evolutionary theories about human origins were accepted.

KEY WORDS: Scientific racism, scientific rationality, human biology, XIXth century.

\section{La «violencia simbólica» de la biología humana en el estudio científico de las 'razas'(1850-1900)}

Durante la segunda mitad del siglo XIX, y en los países más civilizados de «occidente», el más descarnado racismo sobre los pueblos de origen no europeo, lejos de considerarse una ideología perniciosa, llegó a constituir, para la inmensa mayoría de la población educada -incluso para muchos de aquellos que se mostraban enérgicamente en contra de instituciones como la esclavitud-, el resultado lógico de una verdad demostrada por las ciencias naturales más avanzadas del periodo. La enorme violencia conceptual de la biología evolutiva humana, ejercida sobre las comunidades más débiles del planeta desde el punto de vista económico y militar, tomó en la práctica la forma de una Verdad irrefutable para muchos de los espíritus más cultivados de la ciencia norteamericana y europea. Consciente o inconscientemente puesta al servicio de un orden social demencial -el esclavismo o el imperialismo burgués decimonónico-, la violencia simbólica implícita en el discurso técnico de la biología humana ortodoxa del periodo finisecular sirvió para legitimar una violencia directa y material impuesta por la fuerza sobre quienes fueron descritos biológicamente -en términos generales- como seres semihumanos o quasi-humanos o, en último término, no tan humanos como el hombre blanco $^{1}$. Los africanos negros, los esclavos de las plantaciones americanas, los aborígenes australianos, las tasmanas, los indios botocudos, las malayas, los pig-

1 Sobre este asunto, en general, cf. SÁNChEz ArTEAGA, J. M., La razón salvaje. La lógica del dominio: tecnociencia, racismo y racionalidad, Madrid, Lengua de Trapo, 2007. 
meos, los nativos coloniales, así como las mujeres en general, etc., fueron condenados a una inferioridad biológica inalterable por parte de la biología evolutiva decimonónica. La gran ciencia de fines del siglo XIX situó a todos estos grupos humanos en un plano de nítida inferioridad evolutiva, de acuerdo con una fantasmagórica concepción de la esencia natural de la especie humana, ajustada a los estándares y a los intereses de la burguesía blanca de fin de siglo. El consenso científico acerca de la superioridad natural del hombre caucásico fue tan amplio que ni siquiera los científicos más contrarios a la trata de esclavos, o a la hipótesis poligenista -defensora de que las razas humanas eran especies diversas-, ni siquiera hombres como T. H. Huxley, Armand de Quatrefages, o el propio Darwin, pudieron sustraerse al paradigma racista de su tiempo. Como señalan Brace y Montagu a propósito del racismo de la antropología física ortodoxa en el siglo XIX, «el hábito de percibir a los seres humanos de forma estereotipada era tan fuerte que incluso Darwin fue incapaz de librarse de él al tratar con el problema de la variabilidad humana» ${ }^{2}$. Ni siquiera los poquísimos intelectuales no caucásicos que, dentro del «occidente» blanco finisecular, habían tenido la oportunidad de escribir su visión sobre las relaciones raciales, pudieron encontrar otro discurso socialmente legítimo para contradecir los dictámenes demenciales de la biología occidental sobre la jerarquía natural de las razas. Incluso la crítica contemporánea de la cuestión racial por parte de los no-caucásicos educados en Occidente se vio embrujada bajo los efectos narcóticos del consenso alcanzado por la antropología biológica de vanguardia. En los Estados Unidos, por ejemplo:

La confirmación científica de la inferioridad del negro fue tan formidable, que incluso algunos intelectuales de color llegaron a aceptar tanto el marco evolucionista como el aparente destino que aguardaba a los negros en un combate racial perdido de antemano. En «El progreso de una raza», un estudio publicado en 1898 por los hombres de color Henry F. Kletzing y William H. Crogman [...] los autores aceptaban por completo la evidencia de la mortalidad entre los negros, así como la marcha progresiva de la civilización anglosajona. Los neozelandeses, los tasmanianos ${ }^{3}$, los habitantes de las islas del Pacífico, y los

2 Brace, C. L.; Montagu, A., Human Evolution, Nueva York-Londres, Mac Millan, 1977, 2. ${ }^{\text {a }}$ ed., p. 380.

3 Los tasmanianos eran una población que habitaba la isla de Tasmania, en el sur de Oceanía. Sus características físicas los hacían diferentes del resto de las poblaciones oceánicas. Fueron exterminados, literalmente cazados como perros con rifles de batida, por los ingleses, colonos de la isla (que anteriormente había sido utilizada como prisión), en el último tercio del siglo XIX. Los dos últimos supervivientes de uno de los más salvajes genocidios de los que tengo noticia, fueron llevados a Gran Bretaña donde se les estudió y exhibió como a bestias de zoológico, hasta que finalmente murieron sin que quedara más rastro de aquel pueblo que un puñado de esqueletos en varios museos europeos y un gran revuelo de artículos, exactas mediciones y rigurosos cálculos antropométricos en revistas especializadas. En efecto, los antropólogos victorianos se apresuraron para exhibirlos como bestias de interés imperial, y explotaron hasta el último de sus huesos para las vitrinas de los institutos antropológicos del mundo civilizado. Un relato escalofriante de este exterminio, explicado en los términos bio- 
negros sudafricanos ${ }^{4}$, «perecieron no a causa de guerras destructivas..., sino por su incapacidad para vivir en el seno de la civilización decimonónica... Su destrucción no fue debida a ninguna persecución que llegara desde el exterior, sino a una carencia interna de fuerza vital» ${ }^{5}$.

La ciencia del «hombre blanco» llegó a demostrar la superioridad biológica de las poblaciones «caucásicas» de un modo tal que, en la práctica, ésta resultaba un a priori irrefutable para la mayoría de la población educada de las sociedades burguesas del fin de siglo. Todos los cálculos antropométricos de la época parecían confirmarla, todos los gráficos de la anatomía comparada de las razas parecían demostrarla con contundencia. No existían herramientas conceptuales alternativas a las ciencias naturales para la crítica a la ortodoxia antropológica que, al menos hasta el umbral del siglo XX, describió sistemáticamente a la naturaleza humana dentro de un panorama evolutivo de lucha por la existencia entre poblaciones y etnias, definidas muchas veces como verdaderas especies enfrentadas por el dominio de los ecosistemas naturales. Habiendo sido aceptado científicamente que el destino evolutivo de la naturaleza homínida conducía a la dominación de los grupos más aptos (de origen caucásico) sobre las razas degradadas, primitivas y salvajes, las formas características de dominación social en el capitalismo colonial decimonónico quedaron despojadas - para las masas políticas de los grandes Estados burgueses- de toda su significación histórica, y en su lugar fueron revestidas con una brillante aureola de justificación en términos naturalistas. En el imaginario burgués del periodo se estableció así una jerarquía biológica de las razas no muy distinta a la que, décadas después, sería defendida por el nazismo hitleriano en Alemania. De esta forma, el ejercicio sistemático del genocidio y del exterminio practicados a fines del siglo XIX por parte de los grandes estados coloniales sobre numerosas poblaciones indígenas, quedó perfectamente legitimado al encontrar sus fundamentos en el orden pretendidamente racional de la natura-

logicistas del darwinismo más atroz, se encuentra en Hillier Giglioli, E., «I Tasmaniani», en Archivio per l'Antropologia e la Etnologia, vol. 1, 1871. El pueblo tasmanio, sin ciencia y sin historia, había vivido en armonía con su medio hasta la llegada de los colonos británicos.

4 En cuanto al resto de las poblaciones de las que nos hablan los afroamericanos Kletzing y Crogman, también se vieron sometidas a un atroz exterminio por parte de los grandes estados imperialistas. La misma situación de etnocidio generalizado se repetía en todos los rincones del planeta durante el periodo de máxima expansión del imperialismo decimonónico de Occidente. Sobre este asunto, cf. CAMERON, Historia económica mundial, Madrid, Alianza, 1990, capítulo: «El renacimiento del imperialismo occidental. África. Asia. Razones del imperialismo», pp. 338-349; Garaudy, R., Diálogo de civilizaciones, Madrid, Cuadernos para el Diálogo, 1977; Reclus, E., «Negros y Mujiks», en El hombre y la Tierra, 6. Historia moderna, Madrid, Doncel, 1975.

5 Haller, J. S. Jr., Outcasts from Evolution. Scientific Attitudes of Racial Inferiority 1859-1900, Southern Illinois Univ. Press, 1995 [1971], p. 207. 
leza humana, tal y como quedaba definido por las ciencias naturales contemporáneas. Gracias al beneplácito que le había otorgado la comunidad científica, el pre-nacismo imperialista ejercido en las colonias finiseculares pudo revestirse así, sin muchos problemas, como una humanitaria y filantrópica misión civilizadora de las razas superiores sobre sus parientes biológicamente subdesarrollados. Ésta, al menos, fue la percepción socializada de las masas instruidas por la biología occidental ortodoxa. El racismo implícito en la biología evolutiva de las sociedades imperialistas de fin de siglo, predicado como una Verdad demostrada en todas las universidades europeas y norteamericanas hacia 1900, fue asumida incluso entre los propios pueblos oprimidos de forma no muy distinta a como cualquier conquistador logró siempre inculcar su fe entre los conquistados. Un ejemplo paradigmático del verdadero monopolio simbólico de la ciencia finisecular sobre el imaginario social de los conceptos raciales -así como de la inmensa dificultad de encontrar herramientas teóricas para la crítica del exterminio colonial-, se encuentra en el ya citado testimonio de los afroamericanos Henry Kletzing y William Crogman. Recuérdese que, en su propio país, la esclavitud había estado institucionalizada por el hombre blanco apenas hacía treinta y tantos años. Aún así, en relación con el genocidio cometido en las colonias oceánicas, islas del Pacífico, Sudáfrica, etc., estos dos intelectuales negros, seguramente abrumados ante una cantidad inabarcable de datos científicos que confirmaban técnicamente la superioridad caucásica, mantenían lo siguiente:

El exterminio [de los grupos étnicos citados] se debió al inexorable cumplimiento de una ley tan natural como la de la gravitación. Y recordad siempre que aquellas razas perecieron a pesar de los esfuerzos filantrópicos y humanitarios que se emplearon en intentar salvarlos. Perecieron porque no tenían poder de resistencia interior ${ }^{6}$.

La violencia simbólica de la antropología decimonónica sirvió así, con o sin el beneplácito consciente de los propios científicos del periodo, como el vehículo perfecto para la legitimación cultural de la violencia física ejercida en las colonias sobre las poblaciones de origen extraeuropeo. En pocas palabras, el discurso irrebatible de las ciencias naturales se utilizó para legitimar simbólicamente un proceso de expansión colonial que, en términos materiales, supuso un verdadero genocidio en varios continentes. 
HISTORIA DE LA PSIQUIATRÍA

2. La mitificación biológica de las jerarquías raciales del imperialismo (1850-1900)

No es de ninguna manera que lo imaginario sea para nosotros lo ilusorio. Bien al contrario, le damos su función de real al fundarlo en lo biológico.

Jacques $\operatorname{Lacan}^{7}$

Darwin dedicó todo un capítulo de su Descent of Man, de 1871, al problema candente de La Extinción de las Razas del Hombre ${ }^{8}$. Allí, el sabio inglés había aclarado que «la extinción parcial o completa de muchas razas y sub-razas humanas es un hecho conocido históricamente» ${ }^{9}$. De forma implícita, pero obvia para cualquier lector inteligente de la época, la paulatina desaparición (parcial o completa) de las razas inferiores podía comprenderse, en realidad, como el natural corolario darwiniano del proceso colonial contemporáneo, comprendido en términos de grupos biológicos en lucha. De acuerdo con el sabio inglés, las diferentes subespecies humanas, independientemente de su mayor o menor proximidad con el estadio homínido ancestral, se encontraban en un contexto ecológico de lucha intergrupal por la existencia, en la que la naturaleza actuaba extinguiendo las variedades menos favorecidas en la carrera hacia el progreso. Por supuesto, la identidad de los grupos humanos menos favorecidos en el combate evolutivo por la supervivencia era obvia para Darwin. Dando por cierta la inferioridad biológica de las razas no civilizadas, Darwin se enfrentó a la cuestión del «retroceso poblacional» de estos pueblos (debido, en muchos casos, a un auténtico exterminio), así como a la pérdida de sus tierras y de sus fuentes de riqueza a manos del colono blanco, en términos de pura lógica natural: el imperialismo decimonónico, con sus trágicas consecuencias genocidas, debía interpretarse como un resultado inapelable de las leyes de la zoología y de la lucha por la supervivencia. Imbuido, como el resto de los evolucionistas de su tiempo, de los prejuicios raciales victorianos, y dando por sentada una incuestionable analogía evolutiva entre el nativo colonial y el hombre primitivo, Darwin llegó al punto de no ver, en el exterminio real de numerosos pueblos a manos de la «raza caucásica» a la que él mismo pertenecía, más que el desarrollo implacable de las leyes biológicas del progreso:

7 Lacan, J., «De un silabario a posteriori», Escritos, México-Buenos Aires, Siglo XXI, 2003, vol. 2, p. 702 .

Cf. Darwin, Ch., The Descent of Man, and Selection in Relation to Sex, Londres, John Murray, 1871, 2 vol., «On the Extinction of the Races of Man», p. 236 y s.

9 DARWIN, 1871, p. 236. 
Todo lo que sabemos sobre los salvajes, o lo que puede inferirse de sus tradiciones y de los antiguos monumentos [...], muestra que desde los tiempos remotos las tribus exitosas han suplantado a las demás. Relictos de tribus extinguidas u olvidadas han sido encontradas en todas las regiones civilizadas de la tierra, en las llanuras de América, y en las islas lejanas del Océano Pacífico. Actualmente, las naciones civilizadas están suplantando a las naciones bárbaras en todas partes, excepto allí donde el clima impone una barrera mortífera $^{10}$.

El resultado final de este proceso, tan irrevocable desde un punto de vista biológico como las leyes de la gravitación desde uno físico, no escapaba a la imaginación del sabio inglés:

La proliferación de cada especie y de cada raza se ve obstaculizada continuamente por varias trabas; de esta forma, si cualquier nuevo impedimento, o causa de destrucción, incluso una ligera, se superpone a otra, con toda seguridad la raza decrecerá en su número; y como ha sido probado en todas partes que los salvajes se oponen completamente a cualquier cambio de hábitos -con lo que podría contrarrestarse el efecto de esos impedimentos dañinos-, la disminución del número de sus miembros llevará más tarde o más temprano a su extinción ${ }^{11}$.

Al respecto de la desaparición de pueblos, proceso continuo en la historia humana, Darwin señalaba como dato curioso que Humboldt había encontrado una vez «un loro sudamericano que era la única criatura viva que aún hablaba la lengua de una tribu extinguida» ${ }^{12}$. Por lo demás, Darwin no dudaba en señalar un paralelismo biológico entre el «destino futuro» de las razas 'salvajes' con el de ciertas variedades de «la rata nativa, casi exterminada por la rata europea» ${ }^{13}$ cuando esta última había entrado por primera vez en sus ecosistemas, provocando la práctica aniquilación de los roedores nativos. De esta forma, el inmortal creador de la teoría de la selección natural se apresuró, desde la primera edición de El origen del hombre, a señalar la urgencia con que se debían emprender todo tipo de estudios naturalísticos sobre las razas inferiores prontas a la extinción. El asunto era apremiante, dado el estado de evidente regresión biológica de los salvajes ante la imparable pujanza de la raza blanca en los cinco continentes. El genocidio imperialista suponía, eso sí, un motivo de preocupación científica para Darwin. En efecto, la desaparición de estos pueblos,

\footnotetext{
DARWIN, 1871, p.160.

DARWIN, 1871, p. 240.

Ibídem.

DARWIN, 1871, p. 240.
} 
junto con la probable extinción futura de los monos antropomorfos, significaría la pérdida irrecuperable de un material científico de primera categoría para estudiar los estadios ancestrales del «hombre blanco»:

En un momento del futuro, sin duda no muy alejado si lo medimos por siglos, las razas civilizadas del hombre casi con toda certeza exterminarán y reemplazarán a las razas salvajes a lo largo y ancho del mundo [the civilised races of man will almost certainly exterminate and replace throughout the World the savage races]. Al mismo tiempo, los monos antropomorfos, como ha señalado el profesor Schaafhausen, serán exterminados sin ninguna duda. La distancia entre el hombre y el animal se agrandará, puesto que se extenderá entre un hombre en estado de civilización superior, como podemos esperar, al del Caucásico actual, y algún mono tan inferior como el Babuino, en lugar de como actualmente, entre el negro o el Australiano y el gorila ${ }^{14}$.

Por otro lado, el mismo Darwin había señalado que, en ciertos casos, el grado de autoconciencia mostrado por ciertos nativos de las colonias -como, por ejemplo, las hembras de raza australiana- podían aproximarse al que parecían mostrar los perros más inteligentes:
¿Acaso podemos estar seguros [se preguntaba el sabio inglés] de que un viejo perro con una memoria excelente y un cierto poder de imaginación, como refle- jan sus sueños, nunca reflexiona sobre sus placeres pasados en la caza?, y esto sería una forma de autoconciencia. Y por el lado opuesto, como indica Büchner ${ }^{15}$, qué bajo es el grado en que ejerce su autoconciencia, o reflexiona sobre la naturaleza de su propia existencia la extenuada esposa de un degene- rado salvaje australiano [degraded Australian savage], que apenas usa ningu- na palabra abstracta y no puede contar más allá de cuatro ${ }^{16}$.

En efecto, como afirmaba Darwin, Ludwig Büchner, por su parte, se había mostrado nítido, preciso, rabiosamente científico al respecto del status zoológico de las poblaciones australianas. Sin duda, un occidental podía prescindir de excesivos remordimientos por matar de un balazo en la cabeza a un salvaje oceánico (práctica que, desgraciadamente, fue habitual en numerosas ocasiones durante la segunda mitad del siglo). ¿Acaso era seguro que muchos de aquellos salvajes fueran humanos? Para Büchner, la respuesta era menos clara de lo que podían indicar el sentido común o el espíritu filantrópico de los científicamente desinformados:

14 DARWIN, 1871, p. 201.

15 BüChner, L., Conférences sur la Théorie Darwinienne, 1869, trad. francesa, p. 132. La cita es del propio Darwin.

16 DARWIN, 1871, vol. I, p. 63. 
Existen en la superficie de nuestra tierra hombres, pueblos enteros, formas de ser, caracterizadas por una ausencia completa de todo aquello que el europeo instruido considera como los atributos eternos y necesarios de la humanidad [...]. Incluso el lenguaje articulado, que ciertamente puede considerarse como el atributo más especial del hombre y que, únicamente en el hombre, se produce en conjunción con una mejor conformación de la laringe, del cerebro, junto a la estación erguida y una hábil utilización de la mano, incluso el lenguaje articulado [...] se encuentra en numerosos pueblos salvajes en un tal estado de grosería, de imperfección, que apenas puede denominársele lenguaje en el sentido humano de esa palabra ${ }^{17}$.

Por su parte, el mismo Büchner -autor de uno de los mayores best-sellers científicos del periodo, El hombre según la ciencia- había podido comprobar con cifras exactas, a propósito de la lucha por la existencia entre las 'razas humanas', que «las ventajas de este combate benefician sobre todo al órgano del cerebro, y [que] la experiencia nos enseña que así ha sido siempre en el pasado» ${ }^{18}$. Para este mismo autor, lejos de lamentaciones, la guerra entre las razas debía celebrarse como una bendición caída del cielo para el grupo caucásico, cuyo prodigioso órgano cerebral había evolucionado específicamente desde el combate, por el combate y para el combate:

Los pueblos o las razas retrasadas (como los chinos o los negros americanos) no podrán sostener por mucho tiempo la competencia con el hombre civilizado [...] a menos que hagan suyos todos los auxilios que ofrece la civilización actual [...], ese movimiento civilizador general que ha formado el cerebro europeo, y [a menos que] pierdan más o menos las características de su raza ${ }^{19}$.

Por su parte, perfectamente en armonía con los reputados biólogos anteriores, el alemán Ernst Haeckel, en su Historia de la creación de los seres orgánicos según las leyes naturales -llamada a convertirse en una de las obras más influyentes de las ciencias biológicas de todos los tiempos- no dudaba en pontificar, en términos exclusivamente biológicos, acerca de la dominación imperialista de la raza germánica sobre el resto del mundo. Para Haeckel, «el progreso constante de la civilización por el perfeccionamiento de los ejércitos permanentes $»^{20}$, era un corolario natural de las leyes de la evolución humana que habían conducido a la

17 Büchner, L., L'Homme selon la Science. Son passé, son présent, son avenir, ou D'où venons-nous? Qui sommes-nous? Où allons-nous?, París, C. Reinwald et Cie, 1872, pp. 230-231, trad. del alemán por Ch. Letourneau.

18 BüCHNER, L., L'Homme selon la Science, p. 316.

19 Ibídem.

20 HAECKEL, E., Histoire de la Création des Êtres Organisés d'après les lois naturelles, París, Librairie

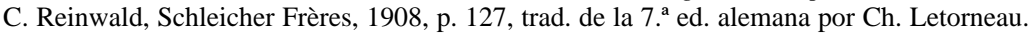


supremacía indoeuropea. De acuerdo con Haeckel, la naturaleza misma, y nadie más que ella, era quien propiciaba que «las guerras se convirtieran naturalmente en fenómenos más y más frecuentes $»^{21}$. En consecuencia, podía considerarse vano todo intento de oponerse con medidas artificiales al proceso natural de expansión del dominio blanco (en especial, anglogermánico) sobre el resto de las razas.

Señalemos de paso que, para Haeckel, la ley de combate que regía la vida entre los grupos raciales, tal y como había sido descrita por la biología darwiniana, debía ser administrada positivamente por una correcta política científica dentro de cada sociedad. Esta práctica de depuración evolutiva de la familia homínida debía realizarse incluso en el seno mismo de las sociedades civilizadas. En este sentido, Haeckel llegó a plantear una nítida defensa biologicista de la pena de muerte. Un uso racional de dicha práctica-aplicada de acuerdo con los principios científicos de la biología humana-, constituiría, según Haeckel, una costumbre saludable para el progreso de nuestro grupo zoológico. En términos naturalísticos -recordemos que la siguiente cita no pertenece al programa político de ningún partido nazi, sino a un libro considerado como un clásico de biología evolutiva-, Haeckel explicaba lo siguiente:

La pena de muerte, cuando se trata de un criminal, de un malvado incorregible, no es solamente un derecho, sino un beneficio para la parte mejor de la sociedad; para ella, resulta una ventaja semejante a la destrucción de la mala hierba en un jardín cultivado. Al igual que únicamente por medio de la erradicación de esas plantas parásitas puede darse a las plantas útiles el aire, la luz, el espacio; de esa misma forma, por medio de la despiadada destrucción de todos los criminales incorregibles, no sólo se facilitaría la lucha por la existencia a la parte sana de la humanidad, sino que además se utilizaría un procedimiento muy útil de selección artificial, pues se eliminaría la posibilidad de que los desperdicios degenerados de la humanidad transmitieran sus funestas propensiones ${ }^{22}$.

En definitiva, con Darwin y sus contemporáneos, la mitología racial decimonónica (por no hablar aquí de las consideraciones científicas acerca de las jerarquías naturales entre los géneros o incluso las clases sociales) encontró una síntesis perfecta, avalada por el lenguaje y el método incontrovertibles (prácticamente irrefutables) de la mejor biología del periodo.

La descripción darwiniana de las jerarquías raciales (en cuya cúspide se hallaban las poblaciones europeas), encontró asiento en un lenguaje científica-

\footnotetext{
21 Ibídem.

22 HAECKEL, E., Histoire de la création des êtres organisés d'après les lois naturelles, París, Librairie C. Reinwald, Schleicher Frères, 1908, ibídem.
} 
mente intachable para la mentalidad victoriana. En concreto, Darwin trazó las líneas de la evolución humana componiendo -consciente o inconscientementeuna nítida escala de superioridad racial, matizada, eso sí, por un humanitarismo monogenista (partidario de la unidad de la especie), aparentemente alejado de los extremos racistas de otros científicos de su tiempo (como Haeckel, Büchner, Broca, Carl Vogt). De esta forma, quizás, puede comprenderse en parte su formidable éxito en la cultura burguesa y colonial del fin de siglo. Como ha sido explicado de forma precisa por el psiquiatra y filósofo francés Jacques Lacan:

El éxito de Darwin parece consistir en que proyecta las predaciones de la sociedad victoriana y la euforia económica que sancionaba para ella la devastación social... a escala planetaria; en que las justifica mediante la imagen de un laissez-faire de los devorantes más fuertes en competencia por su presa natural23.

3. La biología del pueblo elegido: complementariedad de mythos $y$ logos en la definición científica de lo humano

Si entre los primitivos fue el predominio del mito, entre nosotros puede ser por el contrario el predominio de la racionalidad el que nos ha conducido, no al auténtico arcaísmo, sino a uno peor, el de una nueva barbarie. Nada es más «lógico» y más lleno de racionalidad que las lúcidas argumentaciones de Hitler, o los planes de un totalitarismo absoluto. Y a través de esta lógica, el hombre vuelve a un estado de bárbaro primitivismo infinitamente más cruel que aquél que se pudo vivir en los orígenes. Maurice Leenhardt ${ }^{24}$.

Nuestra definición habitual de lo que puede considerarse normal o desviado, superior o inferior, etc., con respecto a la racionalidad o irracionalidad de cualquier discurso -también de los discursos de las ciencias naturales- depende de una convención de carácter histórico-sociológico que varía en el seno de las culturas y a lo largo de la historia. En este sentido, pueden trazarse líneas de desarrollo paralelas en la historia de los conceptos opuestos de racionalidad y de locura. De acuerdo con Remo Bodei: «Los conceptos y las prácticas concernientes a la alienación están estrechamente ligados a la sensibilidad contemporánea referente a la razón y a la irracionalidad y la influencian ampliamente» ${ }^{25}$.

23 LACAN, 2003, I, p. 113.

24 Citado por ReCasens, A. V., «Prólogo», p. 22, en Leenhardt, M., Do Kamo. La persona y el mito en el mundo melanesio, Buenos Aires, Paidós, 1997, pp. 9-25.

25 BodeI, R., Las lógicas del delirio. Razón, afectos, locura, Madrid, Cátedra, 2002, p. 253. 
Un ejemplo ilustrativo del carácter social de nuestro concepto de «racionalidad»: hace algunos años, el senador por Georgia, Richard Russell, en su momento jefe del Armed Services Commitee del Senado Norteamericano y «uno de los tres o cuatro hombres más poderosos de los Estados Unidos» ${ }^{26}$, expresó uno de los mayores despropósitos jamás escuchados acerca del tema que aquí nos concierne, es decir, acerca de la creencia incuestionada en la superioridad de ciertos grupos humanos privilegiados: «Si hay que recomenzar con un nuevo Adán y Eva -dijo- quiero que sean norteamericanos y que estén en este continente y no en Europa» ${ }^{27}$. Como enseguida se preocuparon de destacar algunos intelectuales ligados a las corrientes psiquiátricas alternativas, la libertad del desquiciado senador no fue limitada ipso facto a causa de esta afirmación delirante, a pesar de que, como jefe del comité de armamento del senado americano en los años setenta, su poder material para llevar a cabo la destrucción masiva de miles de «no-americanos» era indiscutible. Al contrario, como se esforzaron en destacar algunos antipsiquiatras de la época, su discurso fue considerado como «coherente», no se encontraron «rastros de delirios o de alucinaciones», y se consideró que «su emotividad estaba en relación con sus sentimientos patrióticos y no existía ninguna sospecha de desorden de pensamiento. Su calma voluntad de ver virtualmente sacrificados a su noción de patriotismo a tres millones de personas sobre la tierra no despert[ó] preguntas sobre su salud mental» ${ }^{28}$. De acuerdo con los estándares de la cultura norteamericana de hace unas décadas, y mientras se continuaran usando las ideas convencionales de dicha sociedad con respecto a la racionalidad y a la salud mental «la definición corriente de locura no alcanza[ría] a hombres como el senador Russell», aunque estos tuviesen, en la práctica, «el poder de destruir la vida sobre el planeta ${ }^{29}$.

Pues bien, por lo que respecta a la racionalidad de la antropología física de fines del siglo XIX, en su discurso teórico sobre la variabilidad biológica en nuestra especie, el historiador contemporáneo de las ideas científicas podría realizar consideraciones parecidas a las hechas por los antipsiquiatras acerca de la racionalidad del senador Russell. Tal y como hemos señalado en las páginas anteriores, durante la segunda mitad del siglo XIX, el concepto biológico de la humanidad comprendía - para una parte representativa de los mejores especialistas en la materia- un conjunto de varios grupos zoológicos perfecta-

26 SCHEFF, T. J., «Razón y salud mental: algunas implicaciones políticas del pensamiento psiquiátrico», en ForTi, L. (ed.), La otra locura. Mapa antológico de la psiquiatría alternativa, Barcelona, Tusquets, 1982, pp. 251-265, p. 261.

27 Ibídem.

28 Ibídem.

29 Ibídem, p. 261. 
mente diferenciados que podían clasificarse según un orden jerárquico de superioridad evolutiva, entendida tanto en términos físicos como intelectuales y morales. Muchos de los mejores científicos del periodo comprendían a estos grupos raciales como verdaderas especies de primates, tan distintas entre sí como podían serlo el perro del lobo, o el caballo del asno. Cuando menos, tal idea constituyó un dogma científico para los antropólogos poligenistas del periodo, entre quienes se contaban algunos de los mejores científicos dedicados al estudio de la evolución humana -patriarcas de las ciencias biológicas como Paul Broca, Carl Vogt, Edgard D. Cope, Ernst Haeckel o Giuseppe Sergi-. Al menos hasta el umbral del siglo XX, un número considerable de prestigiosos antropólogos físicos y evolucionistas de todo Occidente se aplicó en describir la existencia de un abismo biológico entre las distintas razas/especies humanas, aún admitiendo la existencia de un remoto antecesor común para todas ellas. Los argumentos justificantes para esta forma ortodoxa de racismo biológico estuvieron siempre apoyados en conceptos y métodos rigurosamente técnicos, de acuerdo con las corrientes más representativas del paradigma evolucionista del periodo. Las convenciones decimonónicas acerca del significado de lo que podía considerarse como científico, hacían imposible cualquier crítica a la racionalidad de los postulados extremadamente racistas defendidos por la biología humana victoriana -que desde nuestro conocimiento actual de la materia consideraríamos como pseudodelirantes-.

Podríamos decir que, al igual que entre los esquimales y muchas otras sociedades tradicionales - para quienes las palabras con las que se autoidentifican como comunidad (inuit, etc.), tienen el significado específico de ser humano por antonomasia-, o tal y como sucede en la mitología religiosa de hebreos y japoneses -en las que ambos grupos humanos aparecen caracterizados como una especie de pueblo elegido-, así también la biología humana del siglo XIX sirvió para confirmar la existencia de un hiato natural entre «el hombre blanco» y el resto de los grupos raciales. La racionalidad científica no actuó, en este caso, de forma distinta a como el pensamiento mítico ha actuado siempre en todas las civilizaciones del planeta:

Actualmente, los pueblos que conforman todas las grandes civilizaciones se inclinan por interpretar literalmente sus propias figuras simbólicas, y a observarse a sí mismos como favorecidos de alguna manera, en contacto directo con el absoluto. Incluso los politeístas griegos y romanos, hindúes y chinos, que eran capaces de contemplar benévolamente los dioses y costumbres de otros, se ven a sí mismos como superiores; y entre los monoteístas judíos, cristianos y musulmanes, los dioses de los otros no son vistos como dioses, sino como demonios, y sus fieles como impíos. La Meca, Roma, Jerusalén y (en menor medida) Benarés y Beijing han sido, durante siglos y cada una a 
su manera, el ombligo del universo, directamente conectadas -en línea directa- con el Reino de la Luz o con Dios ${ }^{30}$.

De igual forma, las sociedades occidentales del siglo XIX crearon todo un complejo sistema simbólico de racionalización de sus mitologías raciales, a través del cual se identificaron a sí mismas como los grupos elegidos por la naturaleza. Al igual que otras sociedades, y al igual que en los sistemas de pensamiento religioso a los que el racionalismo científico se impuso finalmente -tras una larga fase de influencias mutuas-, la sociedad burguesa del periodo finisecular creyó literalmente en la realidad dibujada por las figuras simbólicas de su cosmovisión tecnocientífica. Las poblaciones no europeas fueron relegadas científicamente a un puesto de cola en las jerarquías naturales del grupo homínido, a una especie de rango zoológico intermediario entre el más evolucionado ser humano (la raza blanca) y el animal. Gracias al enorme prestigio concedido a la biología decimonónica, el carácter puramente histórico y coyuntural del orden geopolítico finisecular quedó transformado en el resultado mismo de leyes científicas aparentemente irrevocables. En este sentido, y expresándonos en los términos de la antropología simbólica de las culturas, podría decirse que el nuevo canon científico de la biología humana darviniana contribuyó, a fines de siglo XIX, a la implantación en occidente de una versión científico-natural del multicultural mito del pueblo elegido ${ }^{31}$.

\section{Conclusiones: el carácter socio-emocional de la definición científica de lo humano}

Como señala el antropólogo cultural Marshal Shalins, «al confiar en la razón simbólica, nuestra cultura no difiere radicalmente de la elaborada por la 'mentalidad salvaje'. Somos tan lógicos, filosóficos y significativos como lo son ellos [...]. Sin embargo, hablamos como si nos hubiéramos liberado de concepciones culturales compulsivas, como si nuestra cultura se edificara a partir de las actividades y experiencias 'reales' de individuos racionalmente dedicados a sus intereses prácticos [...]. Marx escribió que la sociedad primitiva no podría existir a menos que disimulara para sí misma las bases reales de esa existencia, como a tra-

30 Campbell, J., Los mitos. Su impacto en el mundo actual, Barcelona, Kairós, 1993, cap. 1, «Impacto de la ciencia en el mito», p. 19.

31 Véase SÁnchez Arteaga, J. M., «Mythos y Logos en la historia del racismo científico: La biología racial evolucionista en Portugal y Brasil (1859-1900)». De próxima aparición en las Actas del V Congreso internacional «Discursos e Praticas Alquimicas», promovido por la Fundaçâo para a Ciencia e a Tecnología, Ministerio da Ciencia e o Ensino Superior, Portugal. Publicado en http:www.triploV.com. 
vés de formas de ilusiones religiosas. Sin embargo, esta observación puede ser más válida aún en el caso de la sociedad burguesa» ${ }^{32}$. Por lo que aquí nos concierne, no cabe duda de que, examinando la historia de las ideas científicas, los más fundamentales conceptos del pensamiento científico-natural relativos a nuestra especie (raza, género, enfermedad, genética, sexo, locura, arrastran, desde su origen, una imponente carga emocional de carácter sociocultural ${ }^{33}$ ). Las emociones socializadas inconscientemente por los científicos al pensar sobre lo Humano, de acuerdo con el paradigma socioemocional del grupo y el periodo al que pertenecen, contribuyen de forma esencial a configurar la significación práctica de los conceptos y las teorías aplicadas a nuestra especie, ya sea en medicina, en biología, o en psiquiatría ${ }^{34} \ldots$ En este sentido, podemos afirmar que Darwin ideó sus revolucionarias teorías inmerso en el imaginario salvaje de la burguesía imperialista decimonónica, así como que las huellas del pensamiento mitológico acerca del Pueblo Elegido pueden rastrearse tanto en el Génesis como en el Origen del hombre ${ }^{35}$.

Por lo demás, no puede obviarse que nuestra propia forma de racionalidad tecnocientífica ha adquirido, en ciertas ocasiones históricas recientes, un carácter siniestro (¿hace falta decir una palabra más que Hiroshima?). Al igual que el fascismo y el estalinismo del siglo XX, el racismo biológico de los evolucionistas decimonónicos (por no salir de nuestro ejemplo) se convirtió en la ortodoxia científica, apoyado sobre la convicción colectiva de que sus milimétricas directrices raciales corresponderían a un aumento del progreso y la racionalidad humanas en el camino de la historia del conocimiento.

Si fuera absolutamente necesario aceptar que el progreso en la racionalidad constituye el patrón de la historia de los cambios sociales en los paradigmas científicos sobre la naturaleza humana, entonces se haría necesario -en aras de la honestidad intelectual- reconocer que, al menos en determinadas ocasiones, esos mismos cambios históricos -enmarcados dentro de matrices conceptuales con una imponente carga emocional, asociada al imaginario social de la raza, de la enfer-

32 Shalins, M., Cultura y razón práctica. Contra el utilitarismo en teoría antropológica, Barcelona, Gedisa, 1997, p. 215.

33 Sobre este asunto, cf. SÁnchez Arteaga, J. M., «La pervivencia del pensamiento mítico en las teorías biológicas sobre el origen de las razas humanas (1859-1900)», de inminente publicación en las Actas del IX Congreso de la Sociedad Española de Historia de la Ciencia y la Tecnología (Cádiz, Septiembre 2005).

34 Al respecto del papel crucial jugado por las emociones en las representaciones de la mente consciente acerca de la realidad, cf. DAmAsio, A. R., Descartes Error: Emotion, Reason, and the Human Brain, Nueva York, Avon Books, 1995.

35 Sobre este particular, cf. LANDAU, M., «Human Evolution as Narrative», American Scientist, 72, mayojunio, 1984, pp. 262-268; LANDAU, M., Narratives of Human Evolution, Yale University, 1991. También debe consultarse Stoczkowski, W., Explaining Human Origins. Myth, Imagination and Conjecture, Cambridge, Cambridge University, 2002. 
medad, del género, etc.- se han ajustado a un patrón progresivo de racionalidad delirante. Si consideramos que los paradigmas científicos sobre la naturaleza humana constituyen sistemas simbólicos lógico-afectivos, puede afirmarse -al menos metafóricamente- que un cierto delirio científico colectivo parece haber caracterizado determinados cambios de paradigma en el imaginario científico sobre la naturaleza humana:

La esquizofrenia y el delirio surgen cuando los sistemas lógico-afectivos (no sólo el lógico o el afectivo por separado) organizados en el curso de la vida [...] se desorganizan de un modo lábil y confuso y se ven obligados a buscar nuevos equilibrios ${ }^{36}$ : el delirio es la reorganización, a otro nivel, de la desorganización de un sistema normal ${ }^{37}$.

Lejos de apoyar el a priori neopositivista del progreso inevitable hacia una forma superior de racionalidad en la historia de las ciencias, el ejemplo constituido por la historia de la biología decimonónica aplicada a las razas humanas podría describirse, irónicamente, como una especie de sofisticación discursiva de delirios mitológicos -ligados al tema del pueblo elegido-, que fueron asumidos masivamente por las capas educadas de las sociedades burguesas $^{38}$. En cierto modo, la historia de la descripción tecnocientífica ortodoxa sobre la diversidad biológica de nuestra especie durante el apogeo del imperialismo decimonónico puede interpretarse como un catálogo alucinante de autorretratos del hombre blanco burgués, no menos fascinantes, eso sí, que los del «loco» Van Gogh, etc.

En cualquier caso, el delirio científico colectivo sobre nuestra especie, como hecho histórico, no tiene por que ser negativo ni positivo de un modo absoluto. Quizá alguna nueva forma de delirio sostenible sea la mejor terapia de urgencia que podamos aplicar a una sociedad tecnocientífica regida, en tantas ocasiones, por paradigmas lógico-afectivos conducentes a la autodestrucción. Sólo el fomento incesante de una educación para la crítica frente a la tecnociencia contemporánea puede capacitar a la sociedad para ejercer un uso justo y responsable, verdaderamente democrático, del conocimiento. Si pensamos en la ciencia desde una perspectiva histórica comprobaremos que el horizonte de comprensión contemporáneo del orden de la naturaleza humana es tan limitado como cualquier otro en

36 CiompI, L., Logica affettiva. Una ricerca sulla schizofrenia, Milán, 1994, p. 270.

BoDEI, op. cit., p. 109.

38 Etimológicamente, delirar no significa otra cosa que salirse del surco trazado (aplicado en términos científicos, podemos interpretar ese delirio como el salirse del paradigma lógico-afectivo de cada cultura). La «ciencia revolucionaria» tiene siempre un cierto carácter delirante -y como tal viene denigrada por la ortodoxiahasta que los viejos paradigmas de la «ciencia normal» son abandonados de forma definitiva. 
términos lógicos, metodológicos e históricos, pero su capacidad tecnológica para ejercer la destrucción ha adquirido unos caracteres inauditos, como señala U. Beck en La sociedad del riesgo. De ahí que, en este periodo ultratecnificado de retorno al más oscuro espíritu de las cruzadas no puede obviarse la enorme responsabilidad social de la tecnociencia contemporánea. La significación amplia (socioemocional) de las teorías científicas sobre lo Humano -y con ellas, de las nuevas prácticas colectivas a las que esas teorías otorgan una racionalización- no puede captarse si el análisis hermenéutico de la ciencia no alcanza a ver más allá de la dimensión literal del discurso técnico especializado. En definitiva, ninguna forma de investigación científica sobre la naturaleza humana puede presentarse, bajo la coartada de la objetividad enunciativa-descriptiva o del rigor metodológico, como una necesidad inexcusable de la lógica (¿de quiénes?). La lógica y la racionalidad de la ciencia y la tecnología no pueden servir como excusa para ninguna forma de dominación violenta.

* Correspondencia: Juan Manuel Sánchez Arteaga. Dpto. Historia de la Ciencia, C.S.I.C. Duque de Medinaceli, 6, 28001 Madrid.

** Fecha de recepción: 1-X-2006. 